\title{
Early childhood caries and its associations with sugar consumption, overweight and exclusive breastfeeding in low, middle and high-income countries: an ecological study
}

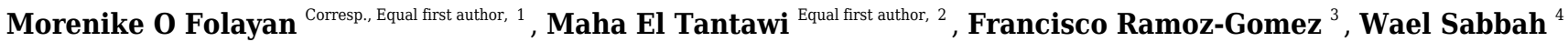 \\ ${ }^{1}$ Department of Child Dental Health, Obafemi Awolowo University, Ile-Ife, Nigeria \\ 2 Department of Pediatric Dentistry and Dental Public Health, Faculty of Dentistry, Alexandria University, Alexandria, Egypt \\ 3 Division of Growth \& Development, Section of Pediatric Dentistry, University of California, Los Angeles, Los Angeles, United States \\ 4 Faculty of Dentistry, Oral \& Craniofacial Sciences, King's College London, University of London, London, United Kingdom \\ Corresponding Author: Morenike O Folayan \\ Email address: toyinukpong@yahoo.co.uk
}

Aim: This ecological study examined the association between the prevalence of early childhood caries (ECC), overweight, country's per capita sugar consumption and duration of exclusive breastfeeding.

Methods: Per capita consumption of sugar in kilograms, percentage of children exclusively breastfed until 6 months of age, percentage of 0-5-year-old children with overweight status, and percentage of 3-5-yearold children with ECC were compared among low-income countries (LICS), middle-income countries (MICS) and high-income countries (HICS). The association between the prevalence of ECC and the study variables, and the effect modification by income region were assessed using multivariable linear regression models. Regression coefficients, confidence intervals, partial eta squared and $p$-values for effect modification were calculated.

Results: The per capita sugar consumption in LICs was significantly lower than in MICs ( $P=0.001)$ and HICs $(P<0.001)$. The percentage of infants who exclusively breastfed up to 6 months was significantly lower in HICs than in LICS $(P<0.001)$ and MICS $(P=0.003)$. The prevalence of overweight was significantly lower in LICs than in MICs $(P<0.001)$ and HICs $(P=0.021)$. The prevalence of ECC was significantly lower in HICs than in MICs $(P<0.001)$. Income was a significant modifier of the associations between the prevalence of ECC, per capita sugar consumption $(P=0.005)$, and exclusive breastfeeding up to 6 months $(P=0.03)$. The associations between the prevalence of ECC and per capita sugar consumption at the global level and for MICs were stronger (partial eta squared $=0.05$ and 0.13 respectively) than for LICs and HICs (partial eta squared $<0.0001$ and 0.003 respectively). Only in MICs was there a significant association between the prevalence of ECC and per capita sugar consumption ( $P=$ 0.002 ), and between the prevalence of ECC the percentage of children exclusively breastfed up to 6 months $(P=0.02)$.

Conclusion: Though the quantity of sugar consumption and exclusive breastfeeding may be a significant risk indicator for ECC in MICs, sugar consumption may be more of a risk indicator for ECC in HICs than in LICS, and vice versa for exclusive breastfeeding. Although ECC and overweight are both sugar-related diseases, we found no clear relationship between them. 
1 Early childhood caries and its associations with sugar consumption, overweight

9

17

*Correspondence and exclusive breastfeeding in low, middle and high-income countries: an ecological study

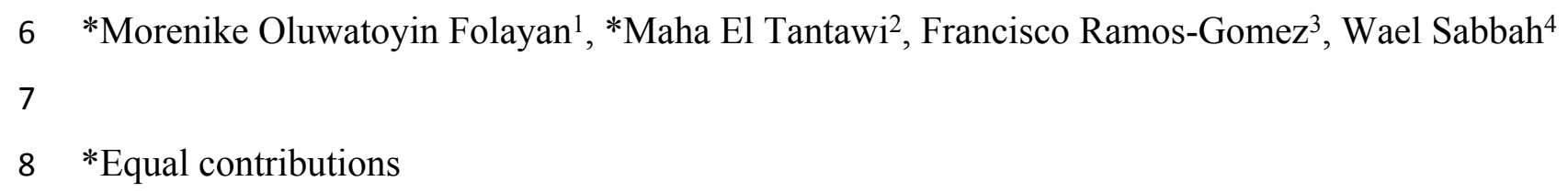

$8 *$ Equal contributions

1. Department of Child Dental Health, Obafemi Awolowo University, Ile-Ife, Nigeria

2. Department of Pediatric Dentistry and Dental Public Health, Faculty of Dentistry, Alexandria 12 University, Alexandria, Egypt

3. Division of Growth \& Development, Section of Pediatric Dentistry, University of California, 4 Los Angeles, Los Angeles, United States.

4. Faculty of Dentistry, Oral \& Craniofacial Sciences, King's College London, University of 6 London, London, United Kingdom

Morenike Oluwatoyin Folayan

toyinukpong@yahoo.co.uk 
47

\section{ABSTRACT}

Aim: This ecological study examined the association between the prevalence of early childhood caries (ECC), overweight, country's per capita sugar consumption and duration of exclusive breastfeeding.

Methods: Per capita consumption of sugar in kilograms, percentage of children exclusively breastfed until 6 months of age, percentage of 0-5-year-old children with overweight status, and percentage of 3-5-year-old children with ECC were compared among low-income countries (LICs), middle-income countries (MICs) and high-income countries (HICs). The association between the prevalence of ECC and the study variables, and the effect modification by income region were assessed using multivariable linear regression models. Regression coefficients, confidence intervals, partial eta squared and p-values for effect modification were calculated.

Results: The per capita sugar consumption in LICs was significantly lower than in MICs ( $\mathrm{P}=$ 0.001) and HICs $(\mathrm{P}<0.001)$. The percentage of infants who exclusively breastfed up to 6 months was significantly lower in HICs than in LICs $(\mathrm{P}<0.001)$ and MICs $(\mathrm{P}=0.003)$. The prevalence of overweight was significantly lower in LICs than in MICs $(\mathrm{P}<0.001)$ and HICs $(\mathrm{P}=0.021)$. The prevalence of ECC was significantly lower in HICs than in MICs $(\mathrm{P}<0.001)$. The income region was a significant modifier of the associations between the prevalence of ECC, per capita sugar consumption $(\mathrm{P}=0.005)$, and exclusive breastfeeding up to 6 months $(\mathrm{P}=0.03)$. The associations between the prevalence of ECC and per capita sugar consumption at the global level and for MICs were stronger (partial eta squared $=0.05$ and 0.13 respectively) than for LICs and HICs (partial eta squared $<0.0001$ and 0.003 respectively). The association between the prevalence of ECC and per capita sugar consumption was significant in MICs $(P=0.002)$, The association between the prevalence of ECC and the percentage of children exclusively breastfed was only significant in MICs $(\mathrm{P}=0.02)$.

Conclusion: The quantity of sugar consumption may be a risk indicator for ECC in MICs and HICs but not in LICs, while exclusive breastfeeding may be a risk indicator for ECC in LICs and MICs but not in HICs. Although ECC and overweight are both sugar-related diseases, there was no clear relationship between the two. 
52 Running title: Sugar, overweight, breastfeeding and early childhood caries

53 
55

56

\section{INTRODUCTION}

Caries and obesity have common risk factors - diet and nutrition [Cregger et al, 2017]. The dietary factor that links the risk factors is high sugar consumption at the expense of vegetables and fruits [Alswat et al, 2016]. Greater access to sugar and refined carbohydrates increases the risk for caries and obesity. For example, during war times in Japan, access to sugar was highly restricted, and caries prevalence dropped significantly, only to increase after the war when access to sugar increased [Takahashi, 1959; Takeuchi, 1961]. Sugar taxation also has reduced sugar consumption and lowered the risk of dental caries and obesity [Yoshida and Simoes, 2018; Schwendicke et al, 2016], whereas individuals who live in proximity to grocery stores and food stores have greater access to sugar with higher risk for caries and obesity [Baker et al, 2006; Tellez et al, 2006; Jetter and Cassady, 2006; Turell et al, 2009; Bodor et al, 2010; Broomhead, 2017]. Although these studies were mostly conducted in Western, high-income countries, similar associations have been observed in several low- and middle-income countries. For example, nutrition transition (increase intake of refined carbohydrates) associated with higher income in low- and middle-income countries is also associated with higher prevalence of obesity and caries [Enwonwu, 2010; Gracey and King, 2009; Popkin et al, 2012].

Breastfeeding modulates the risk of caries and obesity. Exclusive breastfeeding for the first 6 months is protective against overweight and obesity in childhood and beyond [Arenz et al, 2004; Harder et al, 2005; Plagemann and Harder, 2005; Horta and Victora, 2013; Weng et al, 2012]. Multiple pathways have been suggested for this relationship one of which is exclusive breastfeeding precluding inappropriate feeding practices, such as early introduction of complementary foods that are high in free sugar [World Health Organisation, 2014]. On the other hand, breastfeeding more than three times a day [Feldens et al, 2018] and beyond 24 months may increase the risk for ECC [Peres et al, 2017]. To our knowledge, no study has addressed the relationship between caries, obesity and exclusive breastfeeding.

Numerous micro-level studies have been conducted on the link between sugar consumption, obesity and ECC, but none has been conducted to identify the relationship between these factors at the macro-level. Macro-level studies on the relationship between per capita sugar 
85

86

87

88

89

90

91

92

93

94

95

96

97

99

100

101

102

103

104

105

106

107

108

109

110

111

112

113

114

115

consumption, obesity and ECC may give insights about structural interventions that could help achieve population-level disease control. Given the lack of studies in this area and the potential benefit of such information for health promotion policies, we set out to determine the relationship between sugar consumption and the prevalence of ECC, exclusive breast feeding, and overweight status at the global and regional levels. This ecological study is a hypothesisgenerating study on the relationship between the prevalence of ECC, overweight (which is an indicator of high sugar consumption), exposure to breast milk, and country per capita sugar consumption in three World Bank defined income regions.

\section{MATERIALS AND METHODS}

An ecological design was used to determine the relationship between ECC and study variables (per capita sugar consumption, exclusive breastfeeding in the first 6 months of life and overweight) at the global and income region levels. All data were obtained from open sources as explained below.

\section{Percentage of 3-5-year-old children with ECC}

ECC was defined as the presence of one or more decayed, missing due to decay or filled primary tooth surfaces in children less than 72 months of age [Drury et al, 1999]. The data on the prevalence of ECC in 3-5-year-old children extracted from the World Health Organization (WHO) country oral health profile database and other online databases published between 2007 and 2017 by El Tantawi et al [2018] were used for this analysis. No language filter was used for data extraction. The retrieved data were used to calculate the percentage of children with ECC for each of the 193 countries listed by the UN for which data was available. The prevalence of ECC for 3-5-year-old children was computed by dividing the number of children affected by ECC by the total number of children examined in the country, multiplied 100.

\section{Per capita sugar consumption}

Data on sugar consumption were collected from the US Department of Agriculture [2019], Euromonitor International [2019] and Statista [Protectivity Insurance, 2018]. Consumption was measured in per capita kilogram per country for 2017. These data are national averages for all age groups; no age-specific data were available. 
117 Measure of overweight

118 Information on nutritional status was obtained from country-level data produced by the WHO, 119 UNICEF, the World Bank [2018] and UNICEF [2018], covering the period 2007 to 2017. The 120 threshold for defining overweight was established by the WHO-UNICEF Technical Advisory 121 Group on Nutrition Monitoring in relation to standard deviations of the normative WHO Child

122 Growth Standards. Overweight status in children aged 0-5 years old was defined as one standard 123 deviation above median weight-for-height. The prevalence of overweight was calculated as the 124 percentage of children 0-5-year-old children who met the definition.

125

126 Exclusive breastfeeding

127 Country-level estimates of the percentage of infants exclusively breastfed for the first 6 months 128 of life was obtained from the WHO Global Health Observatory data repository [2018]. We used 129 the latest available estimates for the period 2007-2017.

130

131

\section{Economic level}

132 The economic level of countries was based on the 2017 Gross National Income per capita (GNI), 133 calculated with the World Bank Atlas method [2016]. This level was used to group countries into three income categories - low, middle and high. The middle-income category was derived by combining the lower middle and upper middle-income categories. The income regions were as follows: low-income (LICs -GNI of US\$1025 or less); middle-income (MICs - GNI of US\$1026-\$12,475); and high-income (HICs - GNI of US\$12,476 or more).

\section{Data analysis}

140 Per capita consumption of sugar in kilograms $(\mathrm{kg})$, percentage of children exclusively breastfed until 6 months of age, percentage of children 0-5 years old with overweight status, and

142 percentage of 3-5-year-old children with ECC were assessed for normality with Kolmogorov143 Smirnov, Shapiro Wilks tests, QQ plots, and histograms. The percentage of 0-5-year-old children 144 with overweight status and sugar consumption per capita were skewed. Normally distributed 145 variables were compared among the three income regions using ANOVA followed by Scheffe's 146 test for post hoc pairwise comparisons. The Kruskal Wallis test was used to compare the 
147 percentage of 0-5-year-old children with overweight status and per capita sugar consumption in

$148 \mathrm{~kg}$ among income regions followed by post hoc pairwise comparisons using the Dunn-

149 Bonferroni test to adjust for multiple testing.

150

151 Multivariable linear regression analysis was used to assess each of the following relationships in 152 three separate models: associations between the prevalence of ECC and per capita sugar 153 consumption, exclusive breastfeeding and overweight status adjusted for income region. Three 154 other models were constructed to assess the interaction (effect modification) of income region on 155 the associations between ECC prevalence and the other study variables. Regression diagnostics 156 were checked to verify models' assumption. These included drawing scatter diagrams of ECC 157 prevalence against the explanatory variables to check the linearity of the relationships, P-P plots 158 and histograms to assess normality of residuals, and scatter plots of residuals against predicted 159 values to check that the variance of residuals were constant (Appendix A, Figures 1-7).

160 Regression coefficient, 95\% confidence intervals and partial eta squared as a measure of effect 161 size, were calculated. SPSS version 22 (IBM Corp., Armonk, N.Y., USA) was used for statistical

162

163

164

165

166

167

168

169

170

171

172

173

174

175

176

177

178 analysis. Two-sided significance was set at 5\%.

\section{RESULTS}

Combined data for the prevalence of ECC and per capita sugar consumption per income region were available for 77 countries (4 LICs, 43 MICs and 30 HICs), and ECC and percentage of children exclusively breastfed were available for 57 countries (6 LICs, 37 MICs and 14 HICs). Also, ECC and the percentage of 0-5-year-old children with overweight status were available for 53 countries (6 LICs, 40 MICs and $7 \mathrm{HICs}$ ), and ECC and income region data were available for 85 countries (6 LICs, 45 MICs and 34 HICs). Further analysis was restricted per variable for these numbers. The additional (SPSS) file (Appendix B) includes information on all the variables extracted for this study.

Table 1 highlights the association between sugar consumption, breastfeeding, overweight status and ECC in the three income regions. Per capita sugar consumption was significantly lower in LICs than in MICs (median=9.24kg vs $31.94 \mathrm{~kg}, \mathrm{P}=0.01)$ and HICs (median=9.24kg vs $30.48 \mathrm{~kg}, \mathrm{P}=0.005)$. The percentage of infants who were exclusively breastfed up to 6 months was significantly lower in HICs when compared to LICs (mean=15.41 vs 53.37, $\mathrm{P}<0.001)$ and 
179 MICs (mean= 53.37 vs 40.01, $\mathrm{P}<0.001)$. The prevalence of overweight status in 0-5-year-old

180

181

182

183

184

185

186

187

188

189

190

191

192

193

194

195

196

197

198

199

children was significantly lower in LICs when compared to MICs (median= 3.25 vs 7.05, $\mathrm{P}=0.007$ ) and HICs (median= 3.25 vs $7.70, \mathrm{P}=0.039$ ). The percentage of 3 -5-year-old children with ECC was significantly lower in HICs when compared to MICs (mean= 46.01 vs 65.65, $\mathrm{P}<$ 0.001). No significant differences were observed in this variable in LICs and MICs (mean= 63.12 vs $65.65, \mathrm{P}=0.960$ ) or that between LICs and HICs (mean=63.12 vs 46.01, $\mathrm{P}=0.172$ ).

Table 1: Sugar consumption, breastfeeding, overweight and ECC in LICs, MICs and HICs

\begin{tabular}{|c|c|c|c|c|}
\hline Variables & LICs & MICs & $\mathrm{HICs}$ & $\mathrm{P}$ value \\
\hline $\begin{array}{l}\text { Per capita sugar } \\
\text { consumption in kilograms: } \\
\text { Median (IQR) }\end{array}$ & $9.24(8.22)^{\mathrm{a}}$ & $31.94(21.13)^{b}$ & $30.48(17.80)^{b}$ & $0.007^{*}$ \\
\hline $\begin{array}{l}\text { Percentage of infants with } \\
\text { exclusive breastfeeding up } \\
\text { to } 6 \text { months: Mean (SD) }\end{array}$ & $53.37(11.72)^{\mathrm{a}}$ & $40.01(16.75)^{\mathrm{a}}$ & $15.41(10.83)^{b}$ & $<0.001^{*}$ \\
\hline $\begin{array}{l}\text { Percentage of } 0-5 \text { year old } \\
\text { overweight children: } \\
\text { Median (IQR) }\end{array}$ & $3.25(3.40)^{\mathrm{a}}$ & $7.05(7.37)^{b}$ & $7.70(1.4)^{b}$ & $0.03 * q$ \\
\hline $\begin{array}{l}\text { Percentage of } 3 \text { - to 5-year- } \\
\text { old children with ECC: } \\
\text { Mean (SD) }\end{array}$ & $63.12(20.33)^{a b}$ & $65.65(17.85)^{\mathrm{a}}$ & $46.01(23.33)^{b}$ & $<0.001^{*}$ \\
\hline
\end{tabular}

LICs: low-income countries, MICs - middle-income countries, HICs: high-income countries, IQR: inter quartile range, *: Statistically significant at $\mathrm{P}<0.05$, a, b: different letters denote statistically significant differences.

T: Kruskal Wallis test was used followed by Mann Whitney U test for pairwise comparison with adjustment for multiple testing. For the other variables, ANOVA was used followed by Scheff test for pairwise comparison, also with adjustment for multiple testing.

Table 2 shows the association between the percentage of 3-5-year-old children with ECC and the other study variables. Income regions significantly modified the association between the prevalence of ECC and per capita sugar consumption ( $\mathrm{P}$ for interaction= 0.005$)$ as well as the prevalence of ECC and the percentage of children exclusively breastfed ( $\mathrm{P}$ for interaction $=0.03$ ). The only significant associations were the direct relationship between the prevalence of ECC and per capita sugar consumption in MICs $(\mathrm{P}=0.002)$, and the direct relationship between the prevalence of ECC and the percentage of children exclusively breastfed in MICs $(\mathrm{P}=0.02)$. 
201 There was a direct association between the prevalence of ECC and per capita sugar consumption 202 at the global level (regression coefficient=0.18), in MICs (regression coefficient=0.52) and in 203 HICs (regression coefficient=0.05) such that countries with high per capita sugar consumption 204 had high prevalence of ECC. On the other hand, the association between the prevalence of ECC 205 206 207 208 209 210

\section{5}

216

217

218

219 and per capita sugar consumption in LICs (regression coefficient= -0.004) was inverse such that countries with high per capita sugar consumption had low ECC prevalence. The associations between the prevalence of ECC and per capita sugar consumption at the global level and for MICs were stronger (partial eta squared $=0.05$ and 0.13 respectively) than that for LICs and HICs (partial eta squared $<0.0001$ and 0.003 respectively).

Table 2: Association between the percentage of 3-5 year old children with ECC and per capita sugar consumption, percentage of infants with exclusive breastfeeding up to 6 months and percentage of 0-5 years of age children who are overweight by income region and their effect modification (with complete dataset, including UAE per capita sugar consumption)

\begin{tabular}{|c|c|c|c|c|c|}
\hline \multirow[t]{2}{*}{ Variables } & \multicolumn{5}{|c|}{$\begin{array}{l}\text { Association with the percentage of 3-5 year old children with ECC } \\
\text { Regression coefficient }(95 \% \mathrm{CI}) \text {, [partial eta squared] }\end{array}$} \\
\hline & LICs & MICs & $\mathrm{HICs}$ & Global \ & $\begin{array}{l}\mathrm{P} \text { value for } \\
\text { interaction }\end{array}$ \\
\hline $\begin{array}{l}\text { Per capita sugar } \\
\text { consumption }\end{array}$ & $\begin{array}{c}-0.004(-2.50, \\
2.50) \\
{[<0.0001]}\end{array}$ & $\begin{array}{c}0.52(0.20,0.83)^{*} \\
{[0.13]}\end{array}$ & $\begin{array}{c}0.05(-0.15 \\
0.24),[0.003]\end{array}$ & $\begin{array}{c}0.18(-0.01 \\
0.37) \\
{[0.05]}\end{array}$ & $0.005^{*}$ \\
\hline $\begin{array}{l}\text { Exclusive } \\
\text { breastfeeding }\end{array}$ & $\begin{array}{c}0.26 \\
(-0.14,0.66), \\
{[0.03]}\end{array}$ & $\begin{array}{c}0.39 \\
(0.07,0.72)^{*} \\
{[0.10]}\end{array}$ & $\begin{array}{c}-0.004 \\
(-0.85,0.84), \\
{[0.000002]}\end{array}$ & $\begin{array}{c}0.11 \\
(-0.24,0.47), \\
{[0.008]}\end{array}$ & $0.03 *$ \\
\hline $\begin{array}{l}\text { Overweight in } \\
\text { under 0-5 year } \\
\text { old children }\end{array}$ & $\begin{array}{c}-0.76 \\
(-5.79,4.27) \\
{[0.002]}\end{array}$ & $\begin{array}{c}0.33 \\
(-0.64,1.31) \\
{[0.01]}\end{array}$ & $\begin{array}{l}-1.60(-3.96 \\
0.75),[0.04]\end{array}$ & $\begin{array}{c}0.30 \\
(-0.69,1.29) \\
{[0.008]}\end{array}$ & 0.26 \\
\hline
\end{tabular}

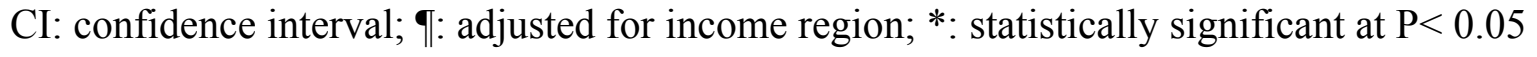

There was a direct association between the prevalence of ECC and the percentage of infants who were exclusively breastfed up to 6 months at the global level (regression coefficient $=0.11$ ), in LICs (regression coefficient $=0.26$ ) and MICs (regression coefficient $=0.39$ ) although this was 
220

221

222

223

224

225

226

227

228

229

230

231

232

233

234

235

236

237

238

239

240

241

242

243

244

245

246

247

248

249

250

statistically significant only in MICs $(\mathrm{P}=0.02)$. The association between the prevalence of ECC and the percentage of infants who were exclusively breastfed up to 6 months in HICs was inverse (regression coefficient $=-0.004$ ). The associations of LICs and MICs (partial eta squared=0.03 and 0.10 ) were stronger than that observed at the global level (partial eta squared $=0.008$ ) and in HICs (partial eta squared $=0.000002$ ).

There was no statistically significant modification by income region for the association between the prevalence of ECC and the prevalence of overweight (P of interaction=0.26).

\section{DISCUSSION}

To our knowledge, this is the first ecological study to determine the association between per capita sugar consumption, the prevalence of exclusive breastfeeding, overweight status and ECC in various income regions. The results highlight a complex relationship between these factors and the prevalence of sugar-related diseases (ECC and overweight). Three especially important observations were these: First, the association between per capita sugar consumption and ECC varied significantly by income regions: HICs had the lowest prevalence of ECC despite having the highest quantity of sugar consumption. Also, although LICs had low sugar consumption, their prevalence of ECC was not significantly different from that of MICs that had higher sugar consumption. Per capita sugar consumption was directly associated with the prevalence of ECC in MICs and HICs, though the association was only significant with MICs. This direct association meant that in these countries with high sugar consumption per capita, the prevalence of ECC was also high. Second, exclusive breastfeeding for 6 months was associated with higher prevalence of ECC in LICs and MICs, though this association was only significant for MICs. The association in HICs was inverse, weak and non-significant statistically. Third, there was no significant association between ECC and overweight and no significant effect modification by income region.

We found no relationship between ECC and overweight status even though both diseases are sugar related. Future studies are needed to clarify the relationships between these diseases before common country-level interventions for ECC and obesity are designed based on the assumption 
251 that both diseases have a common disease pathway and that the impact of sugar control may be

252 similar for both diseases.

253

254 Direct association between ECC and exclusive breastfeeding observed at the global level was

255 present in LICs and MICs but not in HICs although only the association in MICs was significant.

256 This finding may be attributed to confounding by wealth or other factors, which emphasizes that

257 the possible association between ECC and breastfeeding warrants further investigation. At the

258 micro level, prolonged breastfeeding beyond 12 months had been indicted as a risk factor for

259 ECC [Victora et al, 2016]. However, country-level data on duration of breastfeeding for 12

260 months or more were not available to us, so it was not possible to assess the association between

261 duration of breastfeeding and ECC. Our study suggests that exclusive breastfeeding for as little

262 as 6 months may be a risk indicator ECC in some countries but not others. The differences

263 among countries in this association by income region may be attributed to the confounding effect

264 of wealth or oral hygiene. Victora et al [2016] suggested that good oral hygiene may mediate the

265 association between ECC and breastfeeding at the individual level. There are no data on country-

266 level oral hygiene status by age and therefore, so it was not possible to determine the mediating

267 effect of oral hygiene on the associations that we observed.

In addition, our observation that the prevalence of ECC was high in LICs despite the low consumption of sugar may be explained by the impact on ECC of frequency of sugar consumption compared with the quantity of sugar consumed. Studies have shown that both the quantity [Skafida and Chambers, 2018; van Loveren, 2019] and frequency of sugar consumption [van Loveren, 2019] are important in the cause of ECC, but the frequency of sugar consumption may be more of a risk factor than is the quantity of sugar consumed [van Loveren, 2019]. There are no global data on the frequency of sugar consumption, so we could not include that variable in the analysis.

278 Our observation that per capita sugar consumption and overweight status were higher in MICs than in LICs may be explained by increasing country affluence, which is associated with greater access to processed than to agriculture-based diets [Lagerweij and van Loveren, 2015; 
282 access to dental care that reduces the risk of sugar-related diseases. The low prevalence of ECC

283 in HIC despite high per capita consumption of sugar and the significantly lower prevalence of

284 ECC in HICs compared to MICs support this proposition.

285

286 The association between per capita sugar consumption and the prevalence of ECC was positive globally, in MICs and HICs but not in LICs. Perhaps there is a dose response association between sugar consumption and ECC [van Loveren, 2019] beyond which other factors have stronger impact, such as access to health care or healthful foods such as fruits, vegetables and milk [Moynihan and Petersen, 2004; MacKeown et al, 2000; Mayén et al, 2014]. This possibility should be studied further and supports the call to avoid generalization of results obtained from studies in one setting to another.

293

Control of sugar intake in preschool children is important because dietary habits established in early childhood likely are maintained throughout life. Indeed, research suggests a correlation between excessive sugar intake and suicide ideation in adolescents [Pan et al, 2011; Jacob et al, 2019], dementia [Stephan et al, 2010] and cancer mortality [Malik et al, 2019]. Even continuous intake of sugar at low quantity seems to increase the risk for caries in later life [Sheiham and James, 2015]. However, while individual actions to reduce sugar consumption may affect the risk for ECC, our study result suggests that country-level actions may have macro-level impact in MICs and HICs but not in LICs. This finding does not preclude the need for reduced sugar consumption as an individual-level effort to reduce the risk for ECC. These observations need further investigation.

Our results must be interpreted with caution. Ecological fallacy is associated with this type of study, and it is greater at the macro-level than it is at the micro level. This difference is due to aggregation of data resulting in the loss or concealment of certain information [Saunders and Abel, 2014; Hseih, 2019]. Another limitation of our study is its cross-sectional design. It is important to acknowledge that the findings do not prove causality. Also, due to limited countrylevel data, we were unable to adjust for traditional ECC risk factors, such as oral-hygiene, access to dental care and fluoridated water, and the use of fluoridated toothpaste at a young age. Water 
313 well as inequalities in the association between risk factors and ECC prevalence across regions.

314 Future research should address this important point.

315

316 We also were limited in our analysis on per capita consumption of sugar and prevalence of ECC

317 because disaggregated data on sugar consumption by age, sex and socioeconomic status were not 318 accessible. Disaggregated data are urgently needed in view of the growing recognition of the role 319 of sugar in several non-communicable diseases. For example, the Institute of Health Metrics and

320 Evaluation Global Burden of Disease research provides age- and sex-related estimates for 321 tobacco smoking, chewing tobacco and secondhand smoking as comprehensive risk factors for

322 tobacco diseases. However, the Institute provides estimates for diet high in sugar-sweetened

323 beverages, which limits the potential to quantify the prevalence, incidence, burden and mortality

324 of diseases attributed to consumption of all sugars [Institute of Health Metrics, 2017].

325

326

Despite these limitations, the study assessed effect modification by income region that could be

327

328

329

330

331

332

333

334

335

336

337

338

339

340

341

342

343 considered in the planning of future regional and/ or country specific studies. Also, our findings add new information on the macro-level relationship between sugar consumption and ECC, and the relationship between ECC and overweight in pre-school children. The findings highlight differences in sugar consumption-associated risk for ECC by income regions. The study by El Tantawi et al [2018] showed that HICs may have better structural factors - universal health coverage and growth of gross national income - that mitigate the risk of ECC. Therefore, despite high sugar consumption in HICs, access to dental care may be a risk-limiting factor for ECC.

In conclusion, although ECC and overweight have a common risk factor in terms of sugar consumption, the prevalence of ECC was not associated with the prevalence of overweight. The quantity of sugar consumed and prevalence of exclusive breastfeeding were not significantly associated with ECC prevalence globally and were related differently in various income regions. The findings of this study suggest the need to assess diversities in the association between ECC and sugar consumption in countries and individuals with various income levels and the effect of breastfeeding on ECC prevalence in various income regions.

\section{REFERENCES}


345

346

347

348

349

350

351

352

353

354

355

356

357

358

359

360

361

362

363

364

365

366

367

368

369

370

371

372

373

Alswat K, Mohamed WS, Wahab MA, Aboelil AA. 2016. The Association Between Body Mass Index and Dental Caries: Cross-Sectional Study. J Clin Med Res. 8(2):147-52. doi: 10.14740/jocmr2433w.

Arenz, S, Rückerl R, Koletzko B, von Kries R. 2004. Breast-feeding and childhood obesity--a systematic review. International Journal of Obesity and Related Metabolic Disorders. 28(10):1247-1256.

Baker EA, Schootman M, Barnidge E, Kelly C. 2006. The role of race and poverty in access to foods that enable individuals to adhere to dietary guidelines. Prev Chronic Dis. 3(3):A76.

Bodor JN, Rice JC, Farley TA, Swalm CM, Rose D. 2010. The association between obesity and urban food environment. J Urban Health. 87(5):771-781.

Broomhead T. 2017. Neighbourhood effects: spatial inequalities in tooth decay. A thesis submitted in partial fulfilment of the requirement of the degree of Doctor of Philosophy, Unit of Dental Public Health School of Clinical Dentistry University of Sheffield. September. Available at: http://etheses.whiterose.ac.uk/20729/1/Final\%20thesis\%20w_corrections\%20\%20Tom\%20Broomhead.pdf. Accessed 27 May 2019.

Drury TF, Horowitz AM, Ismail AI, Maertens MP, Rozier RG, Selwitz RH. Diagnosing and reporting early childhood caries for research purposes. A report of a workshop sponsored by the National Institute of Dental and Craniofacial Research, the Health Resources and Services Administration, and the Health Care Financing Administration. J Public Health Dent. 1999;59(3):192-197.

El Tantawi M, Folayan MO, Mehaina M, Vukovic A, Castillo JL, Gaffar BO, Arheiam A, AlBatayneh OB, Kemoli AM, Schroth RJ, Lee GHM. 2018. Prevalence and Data Availability of Early Childhood Caries in 193 United Nations Countries, 2007-2017. American Journal of Public Health 108(8):1066-1072

Enwonwu, C. 2010. Global Nutrition Transition Challenges Oral Health. Compendium. 31(2):

Euromonitor International. 2019. Sugar and sweeteners in France. Available at: https://www.euromonitor.com/sugar-and-sweeteners-in-france/report. Accessed 27 May 2019. 
374 Fantom N, Serrajuddin U. The World Bank's classification of countries by income. Policy 375 research paper 7528. 2016. Available at:

376

377

378

379

380

381

382

383

384

385

386

387

388

389

390

391

392

393

394

395

396

397

398

399

400

401

402

403

404 http://documents.worldbank.org/curated/en/408581467988942234/pdf/WPS7528.pdf. Accessed 24 January 2020.

Folayan MO. 2018. A compendium on oral health of children around the world: early childhood caries. Nova Science Publishers Inc. 400 Ser Avenue, Suite 1600, Hauppauge, NY, 11788.

Gracey M, King M. 2009. Indigenous health part 1: determinants and disease patterns. Lancet. 374 (9683): 65-75.

Harder T, Bergmann R, Kallischnigg G, Plagemann A. 2005. Duration of breastfeeding and risk of overweight: a meta-analysis. American Journal of Epidemiology. 162(5):397-403.

Horta BL, Victora CG. 2013. Long-term effects of breastfeeding. Geneva: World Health Organization.

Hsieh JJ. 2019. Ecological Fallacy. Available at: https://www.britannica.com/science/casedefinition. Accessed 16 September, 2019.

Institute of Health Metrics. 2017. GDB compare/Viz Hub. Available at https://vizhub.healthdata.org/gbd-compare/. Accessed 22 July 2019.

Jacob L, Stubbs B, Koyanagi A. 2019. Consumption of carbonated soft drinks and suicide attempts among 105,061 adolescents aged 12-15 years from 6 high-income, 22 middleincome, and 4 low-income countries. Clin Nutr. pii: S0261-5614(19): 30142-6. doi: 10.1016/j.clnu.2019.03.028.

Jetter KM, Cassady, DL. 2006. The availability and cost of healthier food alternatives. Am J Prev Med. 30(1): 38-44.

Lagerweij MD, van Loveren C. 2015. Declining Caries Trends: Are We Satisfied? Curr Oral Health Rep. 2(4): 212-217.

MacKeown JM, Cleaton-Jones PE, Edwards AW. 2000. Energy and macronutrient intake in relation to dental caries incidence in urban black South African preschool children in 1991 and 1995: the Birth-to-Ten study. Public Health Nutr. 3:313-319.

Malik VS, Li Y, Pan A, De Koning, L, Schernhammer E, Willett WC, Hu FB. 2019. Long-Term Consumption of Sugar-Sweetened and Artificially Sweetened Beverages and Risk of Mortality in US Adults. Circulation. 139(18): 2113-2125. 
405 406 407 408 409 410 411 412 413 414 415 416

Mascarenhas AM. 2016. Who Needs More than 1,000 ppm? The Epidemiology of High-Risk Populations. Caries Res. 50(suppl 1): 1-8.

Mayén AL, Marques-Vidal P, Paccaud F, Bovet P, Stringhini S. 2014. Socioeconomic determinants of dietary patterns in low- and middle-income countries: a systematic review. Am J Clin Nutr. 100(6):1520-1531.

Mehta NM, Corkins MR, Lyman B, Malone A, Goday PS, Carney LN, Monczka JL, Plogsted SW, Schwenk WF; American Society for Parenteral and Enteral Nutrition Board of Directors. 2013. Defining pediatric malnutrition: a paradigm shift toward etiology-related definitions. American Society for Parenteral and Enteral Nutrition Board of Directors. $J$ Parenter Enteral Nutr 37(4): 460-481.

Moynihan P, Petersen PE. 2004. Diet, nutrition and the prevention of dental diseases. Public Health Nutrition. 7(1A): 201-226.

Pan X, Zhang C, Shi Z. Soft drink and sweet food consumption and suicidal behaviours among Chinese adolescents. Acta Paediatr. 100(11): e215-22.

Peres KG, Nascimento GG, Peres MA, Mittinty MN, Demarco FF, Santos IS, Matijasevich A, Barros AJD. 2017. Impact of Prolonged Breastfeeding on Dental Caries: A PopulationBased Birth Cohort Study. Pediatrics. 140(1): pii: e20162943.

Plagemann A, Harder T. 2005. Breast feeding and the risk of obesity and related metabolic diseases in the child. Metabolic Syndrome and Related Disorders. 3(3):222-232.

Popkin BM, Adair LS, Ng SW. 2012. Global nutrition transition and the pandemic of obesity in developing countries. Nutr Rev. 70(1): 3-21. doi: 10.1111/j.1753-4887.2011.00456.x.

Protectivity Insurance. 2018. World Sugar Map DATA. Available from: https://docs.google.com/spreadsheets/d/1WgkDa1bTDw9upRnBk_a0gPdscajVBvjuizsmDeEQus/edit\#gid=702504242. Accessed 16 February 2019.

Saunders C, Abel G. 2014. Ecological studies: use with caution. Br J Gen Pract. 64(619): 65-66. doi: 10.3399/bjgp14X676979.

Schwendicke F, Thomson WM, Broadbent JM, Stolpe M. 2016. Effects of Taxing SugarSweetened Beverages on Caries and Treatment Costs. J Dent Res. 95(12):1327-1332. doi: $10.1177 / 0022034516660278$. 
435 Sheiham A, James WP. 2015. Diet and Dental Caries: The Pivotal Role of Free Sugars

436 Reemphasized. J Dent Res. 2015;94(10):1341-1347.

437 Skafida V, Chambers S. 2018. Positive association between sugar consumption and dental decay 438 prevalence independent of oral hygiene in pre-school children: a longitudinal prospective 439 study. J Public Health (Oxf). 40(3): e275-e283.

440 Stephan BC, Wells JC, Brayne C, Albanese E Siervo, M. 2010. Increased fructose intake as a risk factor for dementia. J Gerontol A Biol Sci Med Sci. 65(8): 809-814. doi: 10.1093/gerona/glq079.

Takahashi K. 1959. Statistical study on caries incidence in the first molar in relation with amount 444 of sugar consumption. Jpn J Oral Hyg 9: 136-150.

Takeuchi M. 1961. Epidemiological study on dental caries in Japanese children, before, during and after World War II. Int Dental J 11: 443-457.

Tellez M, Sohn W, Burt BA, Ismail AI. 2006. Assessment of the relationship between neighborhood characteristics and dental caries severity among low-income AfricanAmericans: a multilevel approach. J Public Health Dent. 66(1): 30-36.

The World Bank Group. 2018. List of economies in 2018.

Turrell G, Bentley R, Thomas LR, Jolley D, Subramanian S, Kavanagh AM. 2009. A multilevel study of area socio-economic status and food purchasing behaviour. Public Health Nutr. 12(11): 2074-83. doi: 10.1017/S1368980009004911.

UNICEF. 2018. Malnutrition in Children - UNICEF DATA. Available at: https://data.unicef.org/topic/nutrition/malnutrition/. Published 2018. Updated May 2018. Accessed 16th February, 2019.

United Nations Children's Fud nd, World Health Organization (WHO), World Bank Group. 2018. Levels and trends in child malnutrition: Key findings of the 2018 Edition of the Joint Child Malnutrition Estimates. available at: https://data.unicef.org/wpcontent/uploads/2018/05/JME-2018-brochure-web.pdf. Accessed 27 May 2019.

US Department of Agriculture. 2019. Foreign Agric Service: Production Supply and Distribution. Available at: https://apps.fas.usda.gov/psdonline/app/index.html\#/app/home. Accessed 27 May 2019. van Loveren C. 2019. Sugar Restriction for Caries Prevention: Amount and Frequency. Which Is More Important? Caries Res. 53(2),168-175. doi: 10.1159/000489571. 
466

467

468

469

470

471

472

473

474

475

476

477

478

479

480

481

482

Victora CG, Bahl R, Barros AJ, França GV, Horton S, Krasevec J, Murch S, Sankar MJ, Walker N, Rollins NC; Lancet Breastfeeding Series Group.. 2016. Breastfeeding in the 21st century: epidemiology, mechanisms, and lifelong effect. Lancet. 2016;387(10017):475490.

Weng SF, Redsell SA, Swift JA, Yang M, Glazebrook CP. 2012. Systematic review and metaanalyses of risk factors for childhood overweight identifiable during infancy. Archives of Disease in Childhood. 97(12):1019-1026.

World Health Organisation (WHO). 2018. Global Health Observatory data repository: Exclusive breastfeeding under 6 months data by country. Available at http://apps.who.int/gho/dat.a/node.main.1100?lang=en. Accessed 16 February 2019.

World Health Organisation. 2014. Exclusive breastfeeding to reduce the risk of childhood overweight and obesity: Biological, behavioural and contextual rationale. Available at: https://www.who.int/elena/titles/bbc/breastfeeding_childhood_obesity/en/. Accessed 17 July 2019.

Yoshida Y, Simoes EJ. 2018. Sugar-Sweetened Beverage, Obesity, and Type 2 Diabetes in Children and Adolescents: Policies, Taxation, and Programs. Curr Diab Rep. 18(6): 31. doi: $10.1007 / \mathrm{s} 11892-018-1004-6$ 


\section{Table $\mathbf{1}$ (on next page)}

Table 1: Per capita sugar consumption, exclusive breastfeeding up to 6 months, overweight and ECC in LICS, MICs and HICS

LICs: low-income countries, MICs - middle-income countries, HICs: high-income countries, IQR: inter quartile range, *: Statistically significant at $\mathrm{P}<0.05, \mathrm{a}$, b: different letters denote statistically significant differences. ๆ: Kruskal Wallis test was used followed by DunnBonferroni test to adjust for multiple pairwise comparisons. For the other variables, ANOVA was used followed by Scheff's test to adjust for multiple pairwise comparisons. 
1 Table 1: Per capita sugar consumption, exclusive breastfeeding up to 6 months, overweight and 2 ECC in LICs, MICs and HICs

\begin{tabular}{|c|c|c|c|c|}
\hline Variables & LICs & MICs & HICs & $P$ value \\
\hline $\begin{array}{l}\text { Per capita sugar } \\
\text { consumption in kilograms: } \\
\text { Median (IQR) }\end{array}$ & $9.24(8.22)^{a}$ & $31.94(21.13)^{b}$ & $30.48(17.80)^{b}$ & $0.007 *$ \\
\hline $\begin{array}{l}\text { Percentage of infants with } \\
\text { exclusive breastfeeding up } \\
\text { to } 6 \text { months: Mean (SD) }\end{array}$ & $53.37(11.72)^{a}$ & $40.01(16.75)^{a}$ & $15.41(10.83)^{b}$ & $<0.001^{*}$ \\
\hline $\begin{array}{l}\text { Percentage of } 0-5 \text { year old } \\
\text { overweight children: } \\
\text { Median (IQR) }\end{array}$ & $3.25(3.40)^{\mathrm{a}}$ & $7.05(7.37)^{b}$ & $7.70(1.4)^{b}$ & $0.03 * \Phi$ \\
\hline $\begin{array}{l}\text { Percentage of 3- to } 5 \text {-year- } \\
\text { old children with ECC: } \\
\text { Mean (SD) }\end{array}$ & $63.12(20.33)^{\mathrm{ab}}$ & $65.65(17.85)^{\mathrm{a}}$ & $46.01(23.33)^{b}$ & $<0.001^{*}$ \\
\hline
\end{tabular}

3 LICs: low-income countries, MICs - middle-income countries, HICs: high-income countries, IQR: inter quartile 4 range, *: Statistically significant at $\mathrm{P}<0.05, \mathrm{a}, \mathrm{b}$ : different letters denote statistically significant differences.

5 I: Kruskal Wallis test was used followed by Dunn-Bonferroni test to adjust for multiple pairwise comparisons. For 6 the other variables, ANOVA was used followed by Scheff's test to adjust for multiple pairwise comparisons. 


\section{Table 2 (on next page)}

Association between the percentage of 3-5 year old children with ECC and per capita sugar consumption, percentage of infants with exclusive breastfeeding up to 6 months and percentage of 0-5 years of age children who are overweight by income region and th

LICs: low-income countries, MICs - middle-income countries, HICs: high-income countries Cl: confidence interval $\mathfrak{\eta}$ : adjusted for income region *: statistically significant at $\mathrm{P}<0.05$ 
1 Table 2: Association between the percentage of 3-5 year old children with ECC and per capita

2 sugar consumption, percentage of infants with exclusive breastfeeding up to 6 months and

3 percentage of 0-5 years of age children who are overweight by income region and their effect

4 modification

\begin{tabular}{|c|c|c|c|c|c|}
\hline \multirow[t]{2}{*}{ Variables } & \multicolumn{5}{|c|}{$\begin{array}{l}\text { Association with the percentage of 3-5 year old children with ECC } \\
\text { Regression coefficient }(95 \% \mathrm{CI}), \text { [partial eta squared] }\end{array}$} \\
\hline & LICs & MICs & HICs & Global $₫$ & $\begin{array}{l}\mathrm{P} \text { value for } \\
\text { interaction }\end{array}$ \\
\hline $\begin{array}{l}\text { Per capita sugar } \\
\text { consumption }\end{array}$ & $\begin{array}{c}-0.004(-2.50, \\
2.50), \\
{[<0.0001]}\end{array}$ & $\begin{array}{c}0.52(0.20,0.83)^{*}, \\
{[0.13]}\end{array}$ & $\begin{array}{c}0.05(-0.15 \\
0.24),[0.003]\end{array}$ & $\begin{array}{c}0.18(-0.01 \\
0.37) \\
{[0.05]}\end{array}$ & $0.005^{*}$ \\
\hline $\begin{array}{l}\text { Exclusive } \\
\text { breastfeeding }\end{array}$ & $\begin{array}{c}0.26 \\
(-0.14,0.66), \\
{[0.03]}\end{array}$ & $\begin{array}{c}0.39 \\
(0.07,0.72)^{*} \\
{[0.10]}\end{array}$ & $\begin{array}{c}-0.004 \\
(-0.85,0.84) \\
{[0.000002]}\end{array}$ & $\begin{array}{c}0.11 \\
(-0.24,0.47), \\
{[0.008]}\end{array}$ & $0.03 *$ \\
\hline $\begin{array}{l}\text { Overweight in } \\
\text { under 0-5 year } \\
\text { old children }\end{array}$ & $\begin{array}{c}-0.76 \\
(-5.79,4.27), \\
{[0.002]}\end{array}$ & $\begin{array}{c}0.33 \\
(-0.64,1.31) \\
{[0.01]}\end{array}$ & $\begin{array}{l}-1.60(-3.96 \\
0.75),[0.04]\end{array}$ & $\begin{array}{c}0.30 \\
(-0.69,1.29), \\
{[0.008]}\end{array}$ & 0.26 \\
\hline
\end{tabular}

5 LICs: low-income countries, MICs - middle-income countries, HICs: high-income countries

6 CI: confidence interval

7 T: adjusted for income region

8 *: statistically significant at $\mathrm{P}<0.05$ 